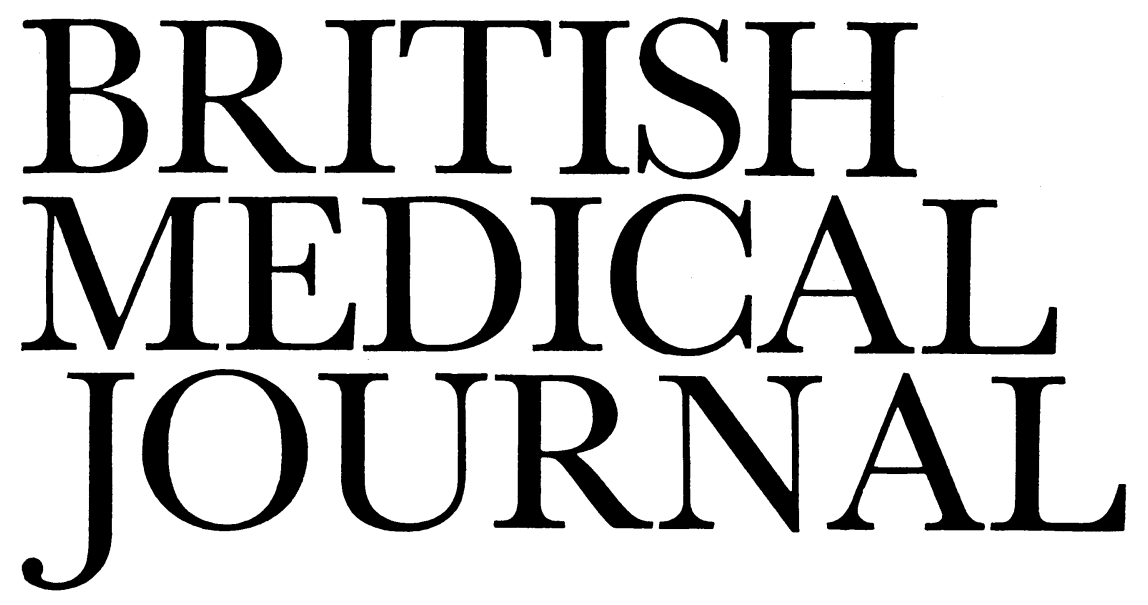

\title{
Maternal nutrition, breast feeding, and contraception
}

One of the many beneficial effects of breast feeding, especially for developing countries, is its contraceptive action. The mecharism by which this is produced, reduced to the simplest possible statement, is the inhibition of ovulation by raised amounts of prolactin in the circulation, in turn under the powerful reflex influence of the suckling stimulus. The evidence is both epidemiological ${ }^{1}$ and physiological. ${ }^{23}$

For any one person lactation is an inefficient contraceptive, but in impoyerished populations, where sustained lactation is the norm, the demographic effect must be important. Somewhat paradoxically, however, for the individual woman prolonged lactation in such societies is usually terminated by the conception of the next child (an observation which long ago in our own society threatened to reauce the matter to the status of an old wives' tale). Furthermore, such traditional societies are noted, despite natural breast-feeding practices, for the vast overrepresentation of small children in the population. Without other measures, breast feeding is thus a manifestly inadequate contraceptive, even at the population level.

Without in any way wishing to sow the seeds of heretical doubt about breast feeding itself (these matters can approach religious infallibility in the minds of adherents to the faith), I examine here the possibility that chronic maternal malnutrition during prolonged breast feeding may contribute to the delay in ovulation. Though prolonged lactation (over 18 months or so) is returning to the fringes of upper middle-class society in the developed world, for the billions of impoverished mothers (by far the majority of women) it is the norm and most of our information must therefore come from them. Almost by definition prolonged lactation coexists with chronic malnutrition world wide. In many underprivileged societies the history of a woman's reproductive life is to conceive soon after puberty, give birth, and lactate for up to a couple of years until the next conception-a cycle often repeated more than once before her own growth is completed. This is followed by a further continuous succession of pregnancies and prolonged lactations, until by her middle-30s she has scarcely ever menstruated, is already becoming senile, and often dies before her more fortunate sisters reach the menopause. In addition such women will typically bear the major share of the hard physical labour of their community, often including the manual ploughing of the fields and the cultivation of crops.
Against this background how astonishing are the physiological mechanisms which "spare" fetal growth and lactation in the interests of the future individual, even though they are eventually defeated $!^{45}$ - but at what cost to the mother?

How much maternal malnutrition reduces fecundity is a complex question. Epidemiological findings, which figure largely in the evidence, may be seductively compelling but are hard to interpret and may even be misleading. Actual maternal nutritional intake is rarely measured in such studies, any more than the extent and intensity of suckling. The former is inferred from maternal anthropometry or from socioeconomic state and the latter often from inadequate or negligible observation. Distinctions are rarely made between fecundity and fertility, between return of menstruation and ovulation, or between the intensity of lactation and suckling. In each of these pairs of factors the second one is the more important and at the same time much more difficult to measure directly. Also the effects of malnutrition are likely to be highly dependent on a widely varying degree and chronicity and type of malnutrition from one society to another, militating strongly against the usefulness of general statements about populations in general. Behavioural factors such as culturally induced sexual abstinence or changes in contraceptive practice are also difficult to take into account. Predictions (for example, of fecundity) are commonly made from mathematical models, and in the end the most that even the best epidemiological studies can provide are casual rather than causal associations based on a large number of possibly questionable assumptions. With these reservations, the more responsible of the demographers have calculated that maternal malnutrition accounts for only a small part of the lactational delay in ovulation and is overwhelmed by the large effects of the continuing lactation itself. ${ }^{1}$

The results of longitudinal physiological studies promise to be more direct and more reliable. The essential ingredients include specificity of nutritional intake and work output, suckling frequency and intensity, blood prolactin activities, activities of other hormones reflecting return of fecundity, as well as lactational and reproductive performance, and infant growth and development in a suitably "homogeneous" sample; all these have not yet been combined in the same project. Such studies would be difficult, but not impossible, and are much needed. 
Perhaps the nearest to this aim, though inevitably still a long way from perfection, are recent studies of women in a village in the Gambia. ${ }^{6}$ These began with an attempt to improve the quantity of the milk output by substantially supplementing the diets of a chronically malnourished and overworked group of women. There was surprisingly little effect on lactationprobably because supplementation from birth onwards is too late in the day. The circulating prolactin activities, however, were substantially altered. In control, unsupplemented, undernourished mothers these rose to very high levels in the first weeks of lactation and fell very slowly thereafter. After 18 months the serum prolactin activities in these women were not much lower than the highest achieved soon after birth by their privileged British sisters, even though milk outputs in the two groups were apparently similar. Dietary supplementation to a level comparable with the intake of the British women substantially reduced the Gambian prolactin activities without there being any change in frequency of breast feeding. Even higher activities of prolactin occurred in unsupplemented Gambian mothers when seasonal factors reduced still further the supply of food. At this time there was a small decrease in the frequency of feeding compared with nutritionally more favourable times of year, so that this is unlikely to have been an important factor.

In a further note the same authors ${ }^{7}$ claim to have shown substantially earlier ovulation in dietarily supplemented mothers, inferred from changes in the circulating concentrations of oestradiol and progesterone; and this seems to be borne out by the occurrence of earlier conceptions. Here again the daily number of breast-feeding episodes was unchanged. One suggestion has been that suckling by the inadequately breastfed babies of the unsupplemented mothers may have been more intense, but since the quality of milk is substantially unaltered by maternal malnutrition, and since its quantity was not altered by this intervention, this objection is hard to sustain.

Whitehead and his colleagues conclude: "The message seems clear, there is a real risk that improving the diet of malnourished lactating women can cause a shortening of birth intervals and, consequently, a rise in birth rate."7

In the light of such emerging evidence it may be that we in privileged society will have to be a little less ready to preach prolonged breast feeding to our less fortunate sisters. No one doubts that a reasonable degree and duration of breast feeding are essential for babies in their impoverished predicament, but would the more reasonable and more positive conclusion not be that we should concentrate on feeding the mothers as well as the babies-and help them find a less cruel and potentially less damaging form of contraception?

\section{JoHn DoBbing}

Professor of Child Growth and Development,

University of Manchester,

Manchester M13 9PT

${ }^{1}$ Bongaarts J. Does malnutrition affect fecundity? A summary of evidence. Science 1980;208:564-9.

${ }^{2}$ Berman ML, Hanson K, Hellman IL. Effects of breast-feeding on postpartum menstruation, ovulation, and pregnancy in Alaskan Eskimos. Am $\mathcal{F}$ Obst Gynecol 1972;114:524-34.

${ }^{3}$ McNeilly AS. Effects of lactation on fertility. Br Med Bull 1979;35:151-4

4 Dobbing J, ed. Maternal nutrition in pregnancy: eating for two? New York: Academic Press, 1981.

5 Waterlow JC, Thomson AM. Observations on the adequacy of breastfeeding. Lancet $1979 ;$ ii :238-41, 2.

${ }^{6}$ Lunn PG, Prentice AM, Austin S, Whitehead RG. Influence of maternal diet on plasma-prolactin levels during lactation. Lancet $1980 ; 1: 623-5$.

${ }^{7}$ Lunn PG, Watkinson M, Prentice AM, Morrell P, Austin S, Whitehead RG. Maternal nutrition and lactational amenorrhoea. Lancet 1981 ; : 1428-9.

\section{Authors of the world, unite. . .}

"Why don't you editors get together, produce a uniform style, and save our secretaries retyping all those references?" authors ask at meetings. The answer is that they have: five years ago, meeting at Vancouver, a group of full-time editors of biomedical journals produced a set of recommendations which at a stroke reduced the number of possible reference styles from 2632 to one. Many prestigious journals have adopted the Vancouver style (or the Uniform Requirements for Manuscripts Submitted to Biomedical Journals, to give its official title); unfortunately, others lag behind and authors still complain that valuable secretarial time is being wasted. So it might fairly be asked whether the new style is logical, acceptable, and workable. Though obviously parti pris, I believe that the answer to all these questions is yes, that editors should adopt the style, and that authors should press them to do so.

The principal bone of contention remains the Harvard system of references (names of authors and dates cited in the text and the reference system in alphabetical order) versus the sequential numbering system of references in the text. After long debate, the decision at Vancouver to follow the second of these was taken on three main grounds. Firstly, the original agreements among the 30 American clinical journals used the numbering system, as did a subsequent agreement among the editors of a group of biochemical journals. Secondly, by 1977 over two-thirds of American biomedical journals were using this style, which is based on that used by the Index Medicus. Thirdly, readers prefer the numbering system to the Harvard style as it makes their task in finding what they want easier and quicker. ${ }^{1}$ Furthermore, the usual so-called advantages of the Harvard system (knowing the "stable" from which the article comes) are not necessarily always present, and in any case intelligence on the part of the author or the subeditor can convey the same information in an article that uses the Vancouver system. Take, for example, a hypothetical article written by nine authors from the liver unit at St Cecilia's Hospital, with the principal and only well-known investigator, Professor John Supremo, appearing last. In the text in Harvard style this might appear as "HLA status was unimportant in the aetiology of primary biliary cirrhosis (Blocks, Tackles, Nuts, et al, 1963)," with-given that the three authors were untried juniors-the article's provenance remaining unknown. In Vancouver style the passage could read: "as Professor Supremo and his colleagues showed at St Cecilia's Hospital in 1963,4 HLA status. ..."

The revised preamble to the Uniform Requirements ( $p$ 1766) emphasises what the document is not: a diktat to editors, who, provided they accept the numbered system of references, can change styles and formats to their own taste. In particular, some editors feel strongly about the position of the date in the reference list, and they are totally at liberty to place this where they like. What acceptance does imply is that if authors have articles styled correctly that are accepted for publication by a journal that has signed the Vancouver convention, that journal will not require the author to make changes to fit its own house style. The legitimate distinction between accepting articles written in accordance with the recommendations and subsequent changes has confused many authors. Thus journals should indicate in their instructions to authors whether they will accept articles written in the Vancouver style and also what elements they will change themselves in the subediting.

The original composition of the International Committee of Medical Journal Editors was broadly based, and it has been 